\title{
EL REI PIRRO DE ROMA EN EL "DOTZÈ DEL CRISTIÀ" DE FRANCESC EIXIMENIS \\ CRÍTICA ENCOBERTA DE LA POLÍTICA SARDA \\ DEl Rei Pere de Catalunya ${ }^{\prime}$
}

CURT WitTLIN

University of Saskatchewan

Saskatoon (Canada)

\section{COM El Filòsof AMALgama RESOL ElS PROBLEMES DEL REI PIRRO DE ROMA}

L'extens volum del Dotzè constitueix una gran summa sobre el bon regiment de la cosa pública. Com hi pertany també la defensa militar, Eiximenis descriu en els caps. 222 a 337 tots els aspectes de l'art de la guerra. En primer lloc tracta de batalles campals, després d'estratègies ofensives i defensives durant un setge. Per a donar una mostra de les dificultats dels assetjants, inventa als caps. 297-299 un carteig entre el "iurisconsultus Pompinianus", que havia anat amb "Pirro, rei de Roma" al setge de Nàpols, al "famòs philòsof en Grècia, Amalgama" (edició de 1484). El jurista demana al savi grec consells sobre tretze terribles mals i plagues que anorreen l'exèrcit assetjador: calor; pudor; mosques, puces, polls, xinxes i paparres; el vi que es torna vinagre; verms intestinals; reuma, dolor de

'Primera part d'una conferència presentada el dia 20 de novembre a la Universitat de Basilea. La segona part, intitulada La "bona astrologia" segons Francesc Eiximenis: Un projecte frustrat de fer servir les arts prohibides per al bé del comú?, apareixerà a "A sol post". Agraeixo a Germà Colon la idea que Amalgania podria ser Amalgama, i a Sergi Gascon la seva revisió de l'adaptació catalana de la conferència. 
dents; diarrea; lassitud general; nafres que no guareixen; els animals que moren. Callaré pel moment el tretzé mal.

Amalgama ofereix solucions per a cada una d'aquestes tretze calamitats. Comença amb alguns consells ben pràctics i factibles. Com a remey per a calor, per exemple, recomana de "fer, en lloc de tendes, caves dins la clausura, escantolades ab fusts, ab spirall per lo fum... Però no en lloc de marjal!". Quant a puces, el filòsof suggereix que els soldats s'untin de cap a peus amb suc d'all, encara que "lo remey aquest és enujós a molts".

D'altres consells ens deixen incrèduls. Contra dolor de dents recomana que el pacient prengui "una herba apellada bursa pastoris... e que la's faés ligar al peu contrari a la dent, ço és, si la dent passionada és al costat dret que la dita herba sia ligada al peu sinistre, e si és al sinistre que sia posada e ligada al peu dret; e de present cessarà la dolor".

Tampoc no ens convencen els remeis basats en artificis astrològics. Contra mosques el filòsof grec aconsella que "Lo sol stant en la terça faç del signe celestial apellat leo, e Mercuri aximateix que hi sia, e sia Mars en aries, e Saturnus no sia retrogradant, lavors, stant lo sol en aytal disposició, fes una mosca solidada d'or pur, e sien les ales d'acer, e sia fet açò en lo dia de Mercuri. E sàpies per cert que llà on aquesta ymatge serà posada, nul temps no hi haurà mosca, per la influència dada a aquesta mosca per la faç celestial, que repugna a natura de mosca". Contra puces deia que "valia fer ymatge de puça constel.lada, axí com dit és de la mosca". (Solidada és, potser, un joc de paraules amb constel.lada, derivat no de de 'sòlid', sinó de 'sol').

Que els astres influeixen en tot d'ací baix, ningú a l'edat mitjana no ho dubtava. El que l'Església combatia era el fatalisme que l'home és completament indefens contra aquestes forces. Amb l'estranyant barreja de consells contra els dotze sofriments dels soldats, Eiximenis vol criticar que aquests procedeixen amb tota mena de trucs contra plagues als quals faríen millor d'acostumar-se -per exemple, les mosques- mentre que accepten amb fatalisme certs mals que sí que deuríen combatre. Aquesta veritat, però, el lector l'aprèn tan sols a la fi del capítol. De moment l'autor es diverteix posant a prova la nostra credulitat amb les seves receptes pseudo-científiques. Quan, es demana, començarà el lector a desconcertar-se? quan a protestar? quan a riure? i quan se li posarà un nus a la gola perquè, per fi, s'ha adonat de l'aspecte tràgic de la situació descrita? 
La tretzena plaga que anorrea l'exèrcit assetjador és que "lo Rey no's vol levar del setge, ans ha jurat que no s'en levarà fins que haja haüda la ciutat".

Amalgama respon i diu: "Açò és naffra del cap irremediable quan lo príncep és foll e no sap dar recapte al regiment. E vosaltres merexeu aquest mal qui li consellàs que aytal guerra faés. Car consellar al gran senyor qui ha poc seny que s'empar de grans affers és consellar-li que's vaja negar, ell e tota sa gent. E quan dius que jurat ho ha que jamés no's levarà del setge fins que haja lo loch, respòs lo dit philòsof que oradura era jurar sa confusió e sa vergonya e prometre de fer ço que no és en sa ma e pot tornar a sa gran destrucció, d'ell e dels seus; e que aytal jurament no obliga, com sia contra Déu e caritat del proïsme e amor de ses gents. E si dius que vergonya serà, responc que major vergonya serà si aquells qui són dins saben l'estament del stol e ixen contra vosaltres e us prenen e us maten a tots. E sàpies que príncep qui en aytal risc posa si mateix e ses gents, orat és e la fe ha trencada a ses gents, e ja no deu ésser pus haüt per senyor ne per regidor lur, puys tan poc los prea e tan poc dóna per ells".

El canvi en el to de la carta del filòsof mostra que Eiximenis escriu ara amb plena seriositat. Comencem a sospitar que havia participat en campanyes militars com a predicador i que tenia experiència personal dels problemes allistats per Pompinianus. En el cap. 716 del Dotzè el nostre autor deia: "Demanar de fet d'armes a un frare menor... seria gran follia, com jamés no (fou) en aytals fets". Sembla que volia més bé dir "si jamés no fou". Haurà observat directament com els soldats sabien fer suportables aquests mals amb tota mena d'astúcies. El que els deprimia era el sentiment que arriscaven la seva salut i vida per un psicòpata ufanòs i tossut, encara que coronat. Com reaccionarien si algú vingués a explicar-los que no solament el dret diví i les lleis de l'Església, sinó també els usos legals del seu propi país els permeten de rebel.lar-se i de retreure la fe al seu monarca boig?

Però el setge de Nàpols no va acabar en un motí. "Aquestes repostes (d'Amalgama) foren publicades per Pompià a Pirro rey. E lo dit Pirrus les aprovà fort, ell e son consell, e de present levà's del setge. E féu ley a tostemps que jamés ell ne los seus no jurassen de no levar-se de setge ne de no fugir de camp de batalla quand veessen que raó dictàs a ell e als seus de partir-se'n o de fugir".

Un rei que fa cas dels consells que li escriu un savi religiós: heus ací una típica il.lusió eiximeniana. Però l'autor va cometre en el darrer passatge 
citat un error freudià. Escriu que les respostes del filòsof "foren publicades per Pompià a Pirro". Eiximenis era prou lingüista per saber que "publicar" vol dir 'retre públic, dir al poble' i que aquest verb no pot tenir com a objecte indirecte una sola persona. L'ús d'aquest mot mostra el dilema de tota la vida del nostre frare. Sí, el conseller deu de primer acusar el monarca dels seus errors i vicis en secret. Quan, però, ve per a un home de Déu l'obligació moral de "publicar" desgràcies i calamitats causades innecessàriament per la casa reial?

Hi ha un segon punt en la darrera frase citada que atreu l'atenció. Pompinianus s'anomena ara Pompià. Un simple error de còpia? O és que el canvi de nom és un senyal que hom no ha de fiar-se dels noms propis usats en aquesta història? Amalgama -probablement lectura preferible a Amalgani$a$, amb l'accentuació que sigui (veg. Colon)- és, sens dubte, el nostre propi Eiximenis. Però, qui és Pirro? El Dotzè està dirigit a la societat catalana alta $\mathrm{i}$ instruïda. L'autor podia assumir que els més llestos dels seus lectors sabien que Pirro no era rei de Roma, però un general grec que havia anat a Itàlia per guanyar, amb moltes pèrdues, algunes batalles contra Roma. Hi ha un altre rei que es va embarcar cap a Itàlia per a patir-hi victòries pírriques?

Sí! El rei Pere el Cerimoniós, que tenia problemes amb Sardenya des del 1354 fins a la seva mort l'any 1387.

\section{Com el Rei Pere de Catalunya no sabia Resoldre ELS SEUS PROBLEMES AMB SARDENYA}

El primer de gener de 1354, "per metre cor a les nostres gents", el rei Pere, segons contarà anys després en la seva Crònica, va fer el següent: "Ordenam e acordam... que vinguem personalment a l'església de Nostra Dona de la Mar de la ciutat de Barcelona, e muntam en alguns cadafals que hi havíem fets fer en la gran plaça de la dita esgleia vers la part del fossar major. E nós estiguem vestits de nostres vestidures reials e ab nostra corona al cap. E aquí fem nostre sermó a tot lo poble nostre de la ciutat que ens estava dejús en la dita gran plaça, notificant-los la gran rebellió e traïció que ens havia feta lo Jutge d'Arborea... e (que) nós, axí com a bon pastor, havem acordat de passar a la dita illa per cobrar e refermar e fortificar aquella e tornar-la a la nostra senyoria, dient-hi moltes paraules apropriades al dit fet, axí de la Santa Escriptura com d'altres afers antics qui són dignes 
de recontar. De la qual cosa tot lo poble nostre hac gran consolació e plaer" (cap. V. 33).

On era Eiximenis aquell primer de gener? Gairebé exactament dos anys abans havia rebut a Barcelona els ordres menors eclesiàstics (Massó; Perarnau). Podem assumir que s'hi quedava fins a ordenar-se sacerdot. Ben probablement, doncs, hi era present quan Pere es va comparar amb "el bon pastor".

El rei Pere estava decidit a dirigir personalment aquesta nova expedició a Sardenya. Havia esdevingut sempre més difícil de finançar noves campanyes i trobar gent disposta a participar-hi (Martorí i Roig; Mitjà). Tothom es recordava com en el setge de Iglésias hi havia "tantes de malauties que la major part de tota la gent (de l'infant Alfons) hi morí de malauties". El cronista Muntaner afegeix que l'infant mateix hi enmalaltí, però que abans d'això "ne per metges ne per null hom ell se volgués partir del setge" (cap. 274). El rei Pere, ara, volia donar l'exemple anant ell mateix a Sardenya; fins i tot es feia acompanyar per la seva muller i filla (Meloni). Però la situació en el camp davant l'Alguer es va deteriorar ràpidament. Nogensmenys, el rei va declarar que no es llevaria el setge "si los cavalls s'hic sabia menjar" (Epistolari 117), exclamant "Havem acordat que us estem ací, si tots tems hic sabiem estar, fins que hajam lo dit loch" (Giménez 92). Amb tot i així, amb un realisme lloable, va manar que el seu secretari tornés al regne amb cent-cinquanta cartes per a buscar ajudes (Sevillano 112). Al Consell reial, reunit a Barcelona, escriu: "Quatre gins es trencaren als primers trets... de què vosaltres sots en culpa... Item vos fem saber que queque's diga de la mala sanitat de Serdenya, nós havem trobat tro ací... bons ayres e plaer d'estar en lo dit setge dejús les tendes" (Epistolari 113; Meloni 150). També en la seva carta al comte d'Empúries menciona els "freschs e bons ayres" (Rubió II.105). Al Consell de València envia una carta on imita l'estil que avui coneixem amb el nom de "valenciana prosa", que, sembla, ja era usat en aquells temps: "(que enviïn soldats), mostràn lo sol de la natural dilecció que'ls nostres solen haver e han a nós, per los raigs del qual se fosés aquell gel que'ls nostres sotsmesos han concebut e'l cor de no venir-nos ajudar" (Epistolari 120, nota 9). Heus ací la resposta prosaica que hom va donar al missatger: "Clam-vos mercè que digats al senyor Rey que mellor ayre ha a València que no en Serdenya" (Epistolari 118, nota 6).

El bon aire sard s'havia tornat un tòpic, una broma general. Pere en tenia ell mateix la culpa, com mostra la seva carta al comte de Ribagorça: 
"Nós veem e coneixem lo bon ayre e la noblea d'esta isla de Cerdenya; per ço n'avem fet un sirventès qui conté veritat, translat del qual dins la present vos trametem... E com se diga per alguns lo contrari..., ardidament lo dit sirventès mostrets a tots cells qui veer lo volran" (Rubió I.168; Tasis 156). Aquest poema, malauradament perdut, Pere l'havia redactat a Càller, atendat sobre la collina on hi havia una capella dedicada a Santa Maria de Bon Aire (Català i Roca).

El rei no callava en les seves cartes que la fam regnava en el camp i que molts soldats eren malalts. Això ho dirà després també en la Crònica: "Estant nós en lo dit setge (de l'Alguer) haguem gran fretura de moltes coses necessàries a la nostra host, que era caiguda en malalties, ço és coses medicinals, axí com sucres e altres coses, e volateria e ous, e salses, e vi... Molts (nobles e cavallers) se n'eren ja tornats per malalties que havien haüdes en lo dit setge, e molts que n'hi havia de morts. Se'n tornaren molts... car s'enmalaltiren en lo dit setge" (cap. 5.37). Potser tenim ací un passatge escrit pel rei mateix; altrament podem estar segurs que havia revisat amb molta cura l'esborrador del seu cronista. En una carta del 1375 Pere escriu a Bernat Desclot: "L'altre capítol, qui parla de la rebellió del Jutge d'Arborea, tenim per bo, e que hi sia fet menció de tots los fets, jassia n'hi haja haüts de gran minva nostra, car raó és que s'hi contenen les provisions que nós hi faem. E si Déus volia noure a nós e valer al Jutge, per açò no romania nós no fóssem diligents en los fets; e nostres successors poran veure nostra diligència. E puys que esperam ab Déu en breu conquerir tota la illa, que serà conclusió de tots los fets passats, e axí lexar-hi-ets espahi per guisa que s'hi puga continuar la conquesta que farem de la illa" (Rubió I.263).

Pere no va abandonar mai el seu projecte de subjugar tota l'illa. La seva motivació era sempre la mateixa. La campanya del 1354 la va justificar recordant que "en temps de pau ens proveïm del blat (de Sardenya)" (Martorí), i el 1380 explicarà al príncep hereu que "perduda Serdenya...aximateix (el "tiran" de Sicília) tolrà Mallorques, car les vitualles que Mallorques sol haver de Sicília e de Sardenya cessaran e per consegüent la terra se haurà a desebitar e perdre. E semblantment... Barchinona se desabitarà" (Salavert 213). L'any 1383 criticarà el Parlament per mostrar tan poc entusiasme per a una nova campanya militar (Tasis 330). Crec que podem assumir que el 1386, quan el rei celebrava el cinquantè aniversari de la seva coronació, molts oradors, a tot el país, adulaven el vell monarca per la seva persistència en voler subjugar de facto tota aquella illa. 
Potser el jubileu de la coronació havia estat organitzat exactament com l'any següent els actes públics per a la mort del rei Pere. Aleshores, a València, el Consell encarregà a Eiximenis i a dos altres frares de fer al.locucions públiques en tres places de la ciutat. Per a facilitar-los el treball -o per a recordar-los la línia oficial- hom els va donar un memoràndum d'idees aprofitables en els seus discursos. Hi podem llegir: "Fo bo e cathòlic cristià... de molt gran e ardit coratge contra sos enemics. E axí's mostrà de fet en moltes... guerres que hagué... E senyaladament quant... lo dit senyor tenc assetjat Murvedre, e lo rey de Castella ab tot son poder venc tro a Xiva, donant fama... que's metria entre la ciutat (València) e Murvedre... perquè la ciutat no pogués soccórrer a ell ne a sa ost de gents ne de viandes... jassia tots e los demés grans barons de sa ost e de son consell e altres fossen de opinió e consellassen al dit senyor que per lo dit perill levàs lo dit setge de Murvedre, emperò lo dit senyor...estec ferm tro a tant que Déu li'n hac feta honor... Item, fon senyor molt victoriós, en tant que de totes quantes guerres hagué -jassia en lo començament o en lo mig hagués algunes adversitats e pèrdues- però a la final tots temps guanyava les difinitives; e axí apparec en... la guerra de Cerdenya" (Ivars 75). Eiximenis, un cop més, havia de mossegar-se la llengua per no exclamar: allò eren victòries pírriques!

El jubileu de la coronació coincidia exactament amb els mesos en què Eiximenis estava redactant el Dotzè. Volia almenys per escrit, encara que codificat, declarar la seva veritable opinió sobre la política sarda del rei Pere? Podia esperar que almenys els millors dels seus lectors descobrissin el paral.lelisme Pere-Pirro? Recordem que entre 1384 i 1389 Fernández de Heredia es feia traduir a Avinyó les Vides paral.leles de Plutarc i que el príncep Joan feia aleshores prou tràmits per a procurar-se'n una còpia (Rubió I.326 i 338).

Però criticar el rei Pere no era el més important per a Eiximenis. La seva crítica té valor universal. Monarques tossuts i ufanosos en tindrem sempre, igual que súbdits tímids que accepten, muts, tots mals causats per caps coronats. L'autor vol manifestar, un cop més, aquestes tres màximes: 1. Retirar-se o fugir d'un camp de batalla no té res a veure amb l'honor, sinó és una tàctica estratègica (veg. Dotzè cap. 286); 2. El poble té un dret diví de retirar l'obediència a un rei incapàç o forasenyat; 3 . Un príncep savi fa cas del que li recomanen bons consellers. 


\section{CONCLUSIÓ}

Aquestes tres veritats, l'autor les declara obertament; que està criticant la política sarda del rei Pere ho ha d'amagar. Poc ens ajuda, avui dia, donar tota la raó a Eiximenis. Encara vivia quan el rei Martí I va parlar a les Corts de l'any 1408 de les "innumerables despeses feytes, e encara moltes de les persones trameses (a Sardenya)... perdudes inútilment" (Cortes $\mathrm{V}$ 397). Però va morir poques setmanes abans que, en juny 1409 , el rei escriví al seu fill Martí el Jove, que estava dirigint el setge victoriós del castell de Sanluri: "Tengats bon regiment en vostra persona e us guardats de mals ayres" (Girona i Llagostera), poques setmanes abans que, el $12 \mathrm{de}$ juliol, el darrer hereu legítim de la corona de Catalunya va morir de malària.

Més productiu és, crec, constatar que tenim en els caps. 297 a 299 del Dotzè un exemple de com Francesc Eiximenis escondeix crítiques de fets polítics concrets dels seus temps. En un altre estudi vaig demostrar que el nostre menoret tan sols s'atrevia a declarar el seu antimonarquisme de forma generalitzada -i en llatí. David Viera ho va retre ben credible que "el pogrom de 1391 va commoure (Eiximenis) personalment", encara que no ho escrigui en lloc. Martí de Riquer, en un treball recent, es declara desconcertat que Eiximenis, en el Dotzè dedicat al comte Alfons de Dènia, no mencioni ni la batalla de Nàjera, on aquest havia estat fet presoner, ni el seu fill que per raó d'això patia vint anys com a ostatge exiliat.

Sí, aquests silencis són estranys i s'hauran d'explicar. Però, potser, el silenci d'Eiximenis és menys total de què sembla. D'una banda cal recordar que no sabem què deia el nostre franciscà en les converses amb els seus contemporanis o en els seus sermons. D'altra banda em sembla ben possible que darrera aquells reis desconeguts amb noms estranys ("Perseu, rei d'Armènia; Janus, rei a l'India; Foromeu, príncep africà"; etc.) dels quals ens conta tantes anècdotes hi podria haver personatges famosos en la política -regional o europea, eclesiàstica o seglar- dels seus temps. Falten encara molts estudis, falta col.laboració entre filòlegs i historiadors. I falta, sobretot, que es publiquin les Obres Completes de Francesc Eiximenis. 


\section{BIBLIOGRAFIA I REFERÈNCIES}

1987.

Autors varis: Fundació Jaume I, Barcelona, Pere III el Cerimoniós, Nadala de l'any

ABADAl, Ramon d'A., Pere el Cerimoniós i els inicis de la decadència política de Catalunya, Barcelona, 1972 (original castellà a Historia de España, 14, Madrid, 1966).

ARCE, Joaquín, España en Cerdeña, Madrid, 1960 (trad. it. Milà, 1981).

CASUlA, Francesco Cesare, La Sardegna aragonese, Sàssar, 1990 (trad. cat. La Sardenya catalano-aragonesa, Barcelona, 1985); veg. p. 43 sobre el setge d'Alguer.

CATAlÀ I RocA, Pere (amb Joan Gala i Fernández), Entorn de "Lo bon ayre e la noblea d'esta illa de Sardenya", a "XIV Congresso di Storia della Corona d'Aragona" (1990), vol. 1 (Sàssar, 1993), pp. 139-165.

COLÓN, Germà, Voces internacionales en dos direcciones, a "II Congreso Internacional de Historia de la Lengua Española" (Madrid, 1994), pp. 43-72 (veg. pp. 64-66 sobre amalgama).

EIXIMENIS (Francesc), Dotzè llibre del Crestià, vol. I, ed. València, 1484; vol. II.12. ed. Wittlin et al., "Obres de F.E." 3 i 4, Col.legi Universitari de Girona, 1986-1987 (modernitzo quelcom les grafies).

Giménez SOLER, Andrés, El viaje de Pedro IV a Cerdeña en 1354, "BRABL", 5 (1909-1910), pp. 88-93.

Girona i Llagostera, D., Itinerari del rei en Martí, Barcelona, 1911-1912 (veg. p. 231).

HILlgarTh, Jocelyn, La personalidad política i cultural de Pere III a través de la seva Crònica, "Llengua i Literatura", 5 (1992-1993), pp. 7-102 (trad. cat. de la introducció a la versió anglesa de la Crònica, 2 vols., Toronto, 1980).

IVARS, Andrés, El escritor Fr. Francisco Eximénez en Valencia (1383-1408), original a "Archivo Ibero Americano" 1920-1926; citem la reed. de Pedro Santonja, Benissa, 1989.

Martí I, Rei, Parlament a les Corts del 1408, ed. Real Acad. Hist., Cortes, vol. 5 (Madrid, 1901), p. 397.

MARTORÍ I ROIG, Maria Raquel, Repercussions de la campanya dels reis de la Corona d'Aragó a Sardenya en la història de la vila de Cambrils, a "XIV Congresso di Storia della Corona d'Aragona" (1990), vol. 1, (Sàssar 1993), pp. 423-439.

MASSÓ I TORRENTS, Jaume, Les obres de fra Francesc Eiximenis. Essaig d'una bibliografia, "AIEC", 3 (1909-1910), pp. 588-692, reed. dins Estudis sobre Francesc Eiximenis, vol. 1 (Girona, 1991), pp. 41-172.

Meloni, Giuseppe, Genova e Aragona all 'epoca di Pietro il Cerimonioso, Padua, 1971-1982; veg. vol. 2, "Pietro davanti Alghero".

---, L'Italia medioevale nella Cronaca di Pietro IV d'Aragona, Cagliari, 1980 (amb extrets en català i trad. it.). 
---, Presenza di Saragozza nella spedizione di Pietro IV il Cerimonioso in Sardegna, a "X Congrés d'Història de la Corona d'Aragó" (Saragossa, 1984), pp. 449-458.

MITJȦ, Marina, Barcelona y el problema sardo en el siglo XIV, a "VI Congreso de Historia de la Corona de Aragón" (Sardenya 1957), vol. 1 (Madrid, 1959) pp. 447-475.

Muntaner, Ramon, Crònica, ed. Ferran Soldevila, Les quatre grans cròniques, (Barcelona, 1971 i reed.), pp. 665-943.

PERE III (amb Bernat Desclot), Crònica, ed. Ferran Soldevila, Les quatre grans cròniques (Barcelona, 1971 i reed.), pp. 1003-1225.

---, Epistolari, ed. Ramon Gubern, Els Nostres Clàssics 78, Barcelona, 1955.

PERARNAU, Josep, Documents i precisions entorn de Francesc Eiximenis (c. 1330-1409), "ATCA", 1 (1982), pp. 191-215.

RIQUER, Martí de, Història de la literatura catalana, vol. 2 (Barcelona, 1964, reimp. 1980), veg. pp. 183-189.

--., El arte de la guerra en Eiximenis y el conde de Denia, a "Medioevo y literatura. Actas del V Congreso de la AHLM" (Granada, 1993), ed. J. Paredes, vol. 1 (Granada, 1995), pp. 171-189.

RuBió I LluCh, Antoni, Documents per la història de la cultura catalana migeval, Barcelona, 1908-1921.

SAlavert y Roca, Vicente, Cerdeña y la expansión mediterránea de la Corona de Aragón (1297-1314), Madrid, 1956.

---, El problema estratégico del Mediterraneo Occidental y la política aragonesa, a "IV Congreso de Historia de la Corona de Aragón" (Palma, 1955), vol. 1, (1959), pp. 201-222 (esp. p. 213].

SÁNCHEZ-CuTILlas, Carmelina, Lletres closes de Pere el Cerimoniós endreçades al Consell de València, Barcelona, 1967.

Sevillano Colom, Francisco, Mateu Adrià, protonotario de Pedro IV el Ceremonioso, a "VIII Congreso de Historia de la Corona de Aragón", vol. 2.2 (València, 1970), pp. 103-118 (veg. pp. 112 ss, sobre el setge d'Alguer).

TASIS, Rafael, La vida del rei en Pere III, Barcelona, 1961.

TANGHERONI, Marco, Medioevo Tirrenico: Sardegna, Toscana e Pisa, Ospidaletto-Pisa, 1992 (també a "XIV Congresso di Storia della Corona d'Aragona" (1990), vol. 1, (Sàssar, 1993), pp. 49-88 (veg. pp. 65-104: "Il Regnum Sardinie nell'economia della Corona d'Aragona").

UDINA, Frederic, L'expansió de la Corona d'Aragó al Mediterrani, a "XIV Congreso di Storia della Corona d'Aragona" (1990), vol. 1, (Sàssar, 1993), pp. 113-153.

VIERA, David, Sant Vicent Ferrer, Francesc Eiximenis i el pogrom de 1391, a "Actes del VI Col.loqui d'Estudis Catalans a Nord-Amèrica, Vancouver 1990" (Montserrat, 1992), pp. 243-254.

WITTLIN, Curt, Quae maxime damnant animas principum. Fünf antimonarchische Kapitel im Pastorale des Francesc Eiximenis, "Zeitschrift für Katalanistik" 2 (1989), pp. 98-114. 


\section{RÉSUMÉ}

Les chapitres du Dotzè de Francesc Eiximenis analysés dans cette conférence décrivent les souffrances des soldats pendant un siège. La pire est de savoir que leur roi avait juré d'endurer tout jusqu'à la fin. Eiximenis fait énoncer à un philosophe grec immaginaire des solutions surprenantes à tous les maux et finit par réitérer trois principes: une retraite ou fuite n'est pas nécéssairement honteuse; le peuple a le droit de se soustraire à l'obéissance d'un roi devenu fou; un bon roi écoute bien ses conseillers.

Nous suggérerons que ces chapitres sont un criticisme voilé du projet -toujours frustré- du roi Pierre III de se soumettre toute la Sardaigne. Eiximenis était probablement présent quand le roi annonça en 1354 son départ contre l'île. Il a certainement entendu parler des souffrances pendant le siège d'Alguer, vu que le roi les mencionne dans des douzaines de lettres -dans une il y ajouta son poème sur "l'air si bon" de la Sardaigne- et plus tard dans sa Chronique. La conquête était une idée fixe du roi, et sa persistance a certainement été louée par les orateurs lors des célébrations publiques du cinquantenaire de l'accès au trône en 1386. 1386 était l'année quand Eiximenis rédigeait le Dotzè. Il y cachait son criticisme du roi Pierre -en catalan Pere- en parlant d'un roi Pirro, mais signale au lecteur que ce nom n'est qu'un code en ajoutant l'absurdité que Pirro était roi de Rome.

\section{SUMMARY}

The chapters of Francesc Eiximenis' Dotzè discussed in this paper describe the sufferings of soldiers during a siege. The worst one is that their king has sworn to endure it all to the bitter end. Eiximenis has an imaginary Greek philosopher offer strange solutions for most difficulties and then states three principles: a tactical retreat or flight is not shameful; a mentally deranged king does not have to be obeyed; a good king listens to his advisors.

In this paper it is suggested that these chapters are a veiled criticism of King Peter the Third's lifelong, but frustrated, plans to fully subjugate Sardinia. Eiximenis probably was present at Peter's speech in 1354, where he announced his decision to lead a campaign against the island himself. He was certainly aware of the great sufferings during the siege of Alguer, since the King mentionned them in dozens of letters -in one he added his poem in praise of Sardinia's "good air" - and later in his Chronicle. The subjugation of all of the island was a fixed idea of the King, and we can assume that his stubbornness was lauded in public speeches during the celebrations of the fiftieth anniversary of his coronation in 1386. 1386 was the year Eiximenis wrote the Dotzè. He hid his criticism of King Peter -in Catalan Pereby talking about a King Pirro, but he gives a hint that this name is a code by adding the nonsense that Pirro was king of Rome. 